\title{
MONGOLIA'S POLITICAL TRANSFORMATION: OBSERVATIONS AND COMPARISONS
}

\section{Hashbat HULAN}

As the twentieth century approaches its endow are witnessing epochmaking historical developments in both Asia and Europe. Contrary to the expectations of both socialists and their opponents, the socialist regimes in Eastern Europe and the former Soviet Union collapsed swiftly and thoroughly, and without any external cause such as war. These societies have begun the daunting task of changing from a centrally-planned economy to a market economy, from totalitarian regimes to democratic political systems, and from party- states to building a civil society. In Asia, the same task is facing Mongolia and some of the former Soviet Central Asian republics. In order to fully comprehend the meaning of these recent developments and their implications for the theory and practice of democratic transformation, we need to assess each against the background of a specific transition environment which includes political history, socio-cultural traditions, economic base, and geopolitical position.

The political transformation in Asia is essentially conducted in two different ways as far as the sequence of political and economic reforms and the speed of the change are concerned: one is a decentralized way, found in Mongolia, and the second is an authoritarian bureaucratic way, found in China. Vietnam, and some smaller states in Central Asia. The Mongolian way has come to display the dilemmas of an Asian society struggling to curtail its "Asianncss" and make a breakthrough unto a world of diversity, change, and modernity.

In my brief assessment of Mongolia's transformation process, let me start with an introduction to the sequence of events since 199C and then continue with some of the theoretical and practical issues that Mongolia's experience has brought into focus.

At the end of 1989 and the beginning of 1990, Mongolia found itself in a specific situation. Under the direct influence of glasnost and the emancipation of Eastern Europe, a political and intellectual dissatisfaction with the political dominance of the communist party, the rigidity of the centrally-planned economy. And Mongolia's satellite status became manifest in political protests, demonstrations, and hunger strikes. Mongolian society was an incongruous combination of a traditional economy based on nomadic cattle breeding and of modern elements including industrial enclaves, education, science, culture, and social 
services. The modern elements were directly related and sustained by the country's political patron and economic donor, the Soviet Union. The existence of young intellectuals, professional intelligentsia, urban bureaucracy, and professional working class dependent upon the expansion of the modernization elements created a possibility for social and political aspirations that did not full) icicle the social pressures and political demands of Mongolian society as a whole.

Intellectual and political dissatisfaction led to demands to transform the political regime into one that would incorporate freedom of thought, political choice and social justice. Economic reform was not at the top of the list of the Mongolian democrat's demands. Their intellectual and political aspirations were beyond the traditional socio-political paradigm and would have never been accepted by most people in the country.

The discrepancy between the "intellectual mobilization" in Mongolia and its political manifestation on the one hand and the economic and socio-political reality of a backward Inner Asian society could have made a political defeat of the intellectuals a foregone conclusion. That, however, did not happen in 1990. The major political factor which played a historical role was process of emancipation that swept over the Soviet satellite states, the process of political decolonization.

The suppression of national self-expression, the deception of the "proletarian internationalist" facade which meant a pervasive Sovietization of the political, social, and cultural life, and Mongolia's international satellite status produced a counteraction to the political dominance of the Mongolian People's Revolutionary Party which had come to be associated with Sovietization policies and anti-nationalist repression. The MPRP was seen as a political arrangement for the continuation of the inferior political status of the Mongols. Thus, the party became the quintessential expression of the interests of a foreign power. At the same time, the party was Mongolia s government, the country's prime political institution, the sole repository of political power there. The removal of the Morph's political control and thus of the old regime as a whole was perceived as a means to break away from foreign control. The aims of the democratic and the nationalist revolution overlapped to bring the Anacin regime to an end in 1990.

The democrats' movement enjoyed broad popular support because a democratic political regime meant an independent Mongolia. The Mongolian revolution was a direct extension of the political process of liberalization and the intellectual pursuit of social reform in Eastern Europe and the Soviet Union. It 
followed in the footsteps of the European pattern whereby political reforms served as the major causal force in introducing and implementing economic and social transition policies. The country's recent political history was a replica of the sociopolitical model of European socialist countries, a "satellite model" which identified Mongolia more with Europe than with Asia. Another factor contributing to the "politics first" situation was the combination of democratic and national aspects of the 1990 revolution which I mentioned earlier.

In March 1990, in the face of the biggest threat in its history to its survival, the MPRP changed its leadership, restructured the Government, and abandoned the one-party political system. The country's formal legislature, the People's Great Hurl, adopted amendments to the Constitution providing for a transitional political system and multi-party elections. In July 1990, the country held its first multi-party elections resulting in the formation of a multi-party legislature with the young opposition parties taking forty per cent of the seats and a coalition Cabinet which included representatives of the MPRP reformist faction, the National Progress Party and the Democratic Party. Both the president and the prime minister were elected by the legislature. The new cabinet initiated an ambitious reform package aimed at the rapid transition to a market economy and a functioning democracy.

The major problem for the reformers was to maintain a popular consensus behind the new policies that imposed a very high social and economic cost on people who accustomed to the social services net that the socialist system had provided. Political fragmentation, lack of distinctive policy platforms, inexperience of the democrats' leadership along with a survival strategy of the MPRP which was continuously disowning the Cabinet it had created led to a political debate throughout the country in the second half of 1991 and early 1992,. Despite the bitter political controversy and the increasing disillusionment about the results of the reform which has been associated with a psychological phenomenon of the "instant gratification", the new legislature and the coalition Cabinet had managed to accomplish two major achievements: they set the foundations of a parliamentary democracy and the initial legal and institutional framework to effect the transition to a new economic system based on private property and market institutions. The political and the economic reform were effected simultaneously and the pace had been far greater than in other transitional societies.

The economic reform package included privatization, price liberalization, and establishment of macroeconomic management institutions. The centerpiece of the package has been the privatization of state owned assets which began in 
1991. The banking sector, the budget system, and the tax scheme were restructured. Improvements were made to the trade and payments systems and there has been an attempt to reorientate external trade from its near total dependence on the former USSR and the former CMEA members.

As a result, the private sector has developed rapidly in the past three years with the creation of new private economic entities in addition to privatized enterprises. However, the state remains a major shareholder in many newly privatized enterprises and continues to exercise management control. Also, the free voucher scheme does not immediately lead to injections of capital and entrepreneurship which would result in improved management performance.

The multi-party legislature passed a package of laws institutionalizing the political parties, the parliament, the cabinet, the powers of president and prime minister. A new legal framework was established for independent public organizations, social security institutions, educational and cultural bodies.

One of the most notable successes of Mongolia's political transformation was the change in its international position. Mongolia has visibly transcended its traditional identity as the sole responsibility of Russia and China. An open for-eign policy has enabled the country to establish and improve relations with all the major Western powers. Expansion of international contacts has been seen as instrumental in helping Mongolia offset its overreliance upon either of its two neighbors and guarantee its sovereignty.

Thus, an atmosphere of a dynamic and generally positive change was prevalent in 1991 and early 1992.

The general political consensus in 1991-1992, coupled with the withdrawal of the USSR, made the initial phase of political and institutional reforms relatively easy. The adoption of the 1992 Constitution and the subsequent general elections completed the destruction of the Anacin regime and inaugurated the institutionalization of the new political system. Mongolia has completed this phase in two years whereas Russia and the republics are still in a situation when "the old order is dying, the new cannot yet be born". The country's young parties, which had been struggling to introduce democracy, ceased to be in opposition to the political regime as such and have become a part of the emerging constitutional parliamentary system.

The 1992 Constitution, adopted by the first multi-party legislature fully recognized for the first time in the country's history human rights and freedoms, and the right to own private property including land. The parliamentary elections held in June 1992 to implement the democratic Constitution took place amid an economic crisis that threatened the political and social stability. 
The timing of the economic reform coincided with the termination of Soviet aid and the demise of both the CMEA and later the USSR, exacerbating the plight of the Mongolian economy. The USSR alone had been providing about \$ 800 million annually in grants and loans. In 1990, Mongolia obtained 40 per cent of its consumer goods and 80 per cent of its machinery from the USSR. The external economic shocks resulted in a rapid and substantial decline of the country's GDP (by as much as 15 percent in 1991 and 10 percent in 1992). The output decline has been accompanied by sharp increases in unemployment and inflation (230 per cent in 1991 and 360 per cent in 1992), both new phenomena in Mongolia. By mid 1992, there were acute shortages of foodstuffs, medical supplies, basic consumer goods and essential industrial equipment. The consumption rate was pushed back to the level of the late 1940s and early 1950s. Overall production fell by 40 per cent.

The economic crisis and the political inexperience of the young parties contributed to the victory of the ex-communist MPRP at the parliamentary elections. The current cabinet was formed virtually by a one-party legislature. In June 1993, Mongolia held its first direct presidential elections which brought victory to President Ochirbat. A reformist ex-Coinmunist nominated by the young parties. Thus, the first round of the political and institutional transformation is over now, and so is the post-communist euphoria.

It would not be an exaggeration to say that Mongolia has found itself facing a historical dilemma all modernizing societies of Asia have had to resolve: how to harmonize modernizing goals which may require state imposed mobilization of human and material resources and pressures for an emancipated political and social regime.

At the moment, Mongolia has a formal democracy with a formally institutionalized plurality of information and interests, a transitional economy dominated by bureaucratic interests in the government and by the nomcnklaturaturned-nouveax riches in the emerging private sector, and proloparties as leading intermediaries between the state and individuals instead of a civil society.

The 1992 parliamentary election results have produced a cul-de-sac: the failure of the young democrats to deliver a significant representation in the Parliament made it impossible for them to provide an institutional political opposition which would have made the constitutional structure operate. The opposition paroles have become unable to influence in any significant manner the decision-making process in state bodies and express the growing political and social diversity of the society at all levels of the state machinery. The absence of a true parliamentary opposition is now stalling the formation of a parliamentary 
system and a parliamentary culture. It has considerably scaled down political and institutional pressures for a consistent and coherent continuation of the radical economic reform initiated in 1990 by the coalition Cabinet

A de-facto return to a one-party decision-making system has affected the pace and the substantive content of the legislative reform, the transformation of the old judiciary into an independent branch, the introduction of local selfgovernment principles and modern basics into the administrative concepts, and the establishment of an impartial and professional corps of civil servants.

The Mongolian political impasse is in clear contrast to the results of the political transformation in the societies of Central Europe, but it has a definite affinity to the political process in the less developed societies of South Central Europe and of the former USSR. To cite a few examples: in November 1992, Lithuania became the second country after Mongolia to elect, an ex-communist legislature through a thoroughly democratic competitive political process. In the former Soviet Central Asia, the sociopolitical transformation is now being handled by the former communist leaders with a new Western-style political opposition almost non-existent or politically marginal or even politically persecuted.

If democracy is taken as an institutional arrangement for arriving at political decisions in which individuals endeavor to acquire political office through free competition for the votes of a broadly based electorate, then we must accept full legitimacy of the new political order as set up in those countries through institutionalized elections. Consequently, we must refuse to take outcomes into account including the absence of a spirit of toleration, the tyranny of the majority, and the uncompromising rule of the party that gets first past the post in elections, none of which is consonant with the idea of democracy as a process with a substantive content, i.e. protection of individual freedom. It is precisely here that the questions related to sociocultural traditions and values should be posed: What are specific sociocultural values that either encourage or discourage the establishment of democracy? Can democracy be viable if the idea of individual freedom does not necessarily belong to the set of values espoused by a society? Can democracy be sustained if modernization policies along with traditional values necessitate a collectivist concentrated mobilization of material and human resources? I assume that we could never arrive at certainties but only tentative conclusions that future development may falsify.

In connection with the abovesaid, let me put down several propositions which would help place the issue of models and sociocultural aspects of democratic transition into a historical and logical context. 
1. The transitional societies of Europe and Mongolia are now trying to achieve what has never been done anywhere in the world: to build a market economy and a democratic polity simultaneously. Developing a market economy in the West took hundreds of years, and it was carried out in situations where most citizens (particularly individuals who lost out) did not have the right to vote.

2. International experience shown that democratic reforms in conditions of economic collapse, social dislocations and political instability are harder to achieve than at a time of economic growth and relative prosperity.

3. Establishing market economy institutions and creating viable democratic political and social institutions may not necessarily demand the same sets of sociocultural values: empirical evidence demonstrates that a successful market economy can exist in the absence of democracy.

4. In an established market economy where modernization goals have already been achieved, there are increasing pressures for democracy, which then has more chances to be institutionalized.

5. Individual autonomy in Western culture engendered modern individualism associated with both a successful market economy and a democratic polity.

6. The values of Asian communalism, religious and ethical traditions of Asian societies could be adapted to modern conditions and exploited for the sake of a rapid, deliberate and concentrated modernization. However, they may not be in- strident in fostering a democratic culture.

7. The transition tasks of the former socialist societies are complicated by sociocultural legacies of the old totalitarian order.

8. During the transition from a totalitarian regime with a centrally planned economy to a pluralist political regime with a market economy the key issue is the role of the state in effecting economic and political reforms. Undoubtedly, liberalization of the economy is inconceivable without a dramatic decrease in state economic functions, which are incompatible with a market economy. At the same time, serious dislocation of economic and administrative relationships, disruption of normal operations of major economic institutions, and implementation of radical reform measures necessitate a competent, well organized and efficient state administration and involvement. The latter may degenerate into a bureaucratic model of transition, which creates a counteraction to a more dynamic movement toward both political and economic liberalization.

9. The authoritarian-bureaucratic model of transition implemented in the countries of East Asia has a powerful attraction, which is referred to quite often 
by some officials who are in state bureaucratic positions overseeing the transition. The chances for implementing the authoritarian-bureaucratic model are higher in countries where nation-building and economic modernization have not been completed, e.g. Albania, Rumania, and Ukraine in Europe, Kazakhstan, Kyrgyzistan, and Uzbekistan in Central Asia. In countries where the totalitarian regime has been thoroughly discredited, and state institutions have been radically transformed, the political and social cost of a return to the old leadership and management style might offset possible economic gains.

The type of traditional political culture found in transitional Central Asian societies and the political culture of generations that were brought up under the socialist regimes in Eastern Europe and Russia generally promoted a set of values that could be considered under a generic "collectivist, anti-individualistic" model of political culture. Its major elements include the emphasis on the importance of collective goals and the collective good as opposed to individualistic aims and the individual good, i.e. the priority of the group (the individual could not be considered apart from the collective whole); humility toward the state, i.e. social deference and paternalism (the nation assumes responsibility for its citizens); and the rejection of political equality of all individuals. These types of political culture fostered submissiveness before any form of authority, and passiveness and yielding attitude to please those in power. To illustrate the above, traditional Central Asian societies, including Mongolia, place an extremely high value on obedience to one's parents, to older people, and to "wise men". As a result, there is an informal but rigid mechanism to check formalized freedom of belief and freedom of expression. Socialism emphasized political superiority of individuals belonging to a "politically educated group", i.e. the "wise men".

Nationalism has become one of the key elements of the emerging political culture in the transitional societies. The transitional phase involves frustration, disappointment, and confusion. A vacuum develops between aspiration and attain-ment. When social ideology is discredited, it is nationalism that fills in the vacuum. Both nationalism and totalitarianism liberate people from individual responsibility, that's why it has been easy for communists to turn nationalists and for the population to accept their metamorphosis. The political emancipation of East European countries, nations of the former Soviet Union, and Mongolia has been an important factor in consolidating national self-consciousness and providing a fertile ground for the search of a comprehensible and easily defined culprit- "someone who does not belong to us". In the former Soviet Central Asia, transition to a new social and economic order has coincided with a "sur- 
prise" independence granted from Moscow, or rather Brest. For them, nationbuilding has precedence over other transition goals.

Low political participation is another sign of a transitional society. Humility before the state implies complete delegation of responsibility to the authority, thus no virtue is placed upon social and political self-organization of individuals. In Eastern Europe and Russia, low participation is also explained by the rejection of political structures as "corrupt and useless" which stems from a feeling of political alienation and social distrust.

Further, religious renaissance has brought about two conflicting tendencies: the one- to encourage plurality of religious beliefs and the other- to consolidate conformity and compliance through religious self-assertion of a group/ nation. The latter tendency is dominant in the majority of countries undergoing the transition for it is more relevant to the pragmatic goal of national consolidation and indoctrination.

What arc the values Thai should be encouraged in order to promote a democracy culture? I am deliberately using the verb "to encourage" rather than "to inculcate" or "to implant" for it is doubtful whether democracy could be established through indoctrination. However, values could be encouraged if they are relevant to objective needs, and they are passed on clearly and persuasively by those who hold them to those who do not. Now that the societies in Eastern Europe and Mongolia no longer have the dubious benefit of state controlled education or of single education/sociolization institution, the primary focus should be set upon other forms of political socialization such as decentralized educational institution, media, and NGOs.

The changes in education involve introduction of the new curriculum with an emphasis on a politically unbiased presentation of social sciences and of extracurricular activities aimed at shaping new attitudes toward politics. The latter refers to giving a civic education training whereby one learns the rules for playing the nation's political game, whatever the game might be. Establishing a diversity of extracurricular activities for students and special non-profit centers to include adults demand investment both by governments and directly by citizens. Naturally, economic reconstruction and modernization goals restrict educational policies to universal education goals and generate temptation for governments to indoctrinate the population.

The dismantling of the system of absolute control over the mass media seems to have been one of the most important achievements of transition in Eastern Europe, Russia, and Mongolia. It has given continuity to the unique 
and very brief moment of liberty, innovation and diversity which we experienced in 1989-1990.

If government control of media has become lax, then communications underdevelopment and commercialization of the media have appeared as major hurdles to a pragmatic use of the media as a means of civic education and socialization. Another area of concern is ensuring fair access to the media, protecting the rights of journalists, and guaranteeing freedom of information. The legislation covering these issues has been contradictory and the government agencies set up to regulate the media have become bureaucratic labyrinths. The transitional societies have seen the emergence of media as the powerful election campaign instrument. Buying access to the media for political purposes and the superficiality of campaign coverage and political advertizing have led to a decrease in the public's trust in the impartiality and informational effectiveness of the media. Further, the creation of private national newspapers, radio and TV again requires considerable investment.

Participation of individuals in political and non-political groups and their effective operation constitute a prerequisite for introducing civil society structures in the countries which either lack any traditions of civil society (Asian societies in transition) or have failed to retain pluralist institutions of civil society (Eastern Europe and Russia).

Political parties in transitional societies are themselves in flux and constant realignment. They do not have large and permanent bases of support among voters. Because they do not command firm allegiance, some of them are easily eliminated. The Civic Forum in the then Czechoslovakia, Solidarity in Poland, and Democratic Russia all suffered extinction or near-extinction as soon as the first post communist elections were held. Most political parties do not represent interests of well defined and clear-cut social groups. Their prime purpose is to serve as platforms for personalities who belong to them. In a number of countries, financial constraints of the new political parties have effectively led to their marginalization (Russia, Mongolia, and Ukraine). A stable democracy needs strong parties with a loyal social base. And it is both the political will of the ruling elite and the gradual emergence of social groups dependent upon market allocation of resources that are going to determine whether these societies would be able to sustain a civil society and a culture accompanying it.

The key problems that Mongolia has to resolve have more similarities with the problems of the societies in Eastern Europe and the former USSR. The specific aspects of Mongolia's problems stem from the constraints of its geographi- 
cal situation, the level of its economic development, the geopolitical environment, and the human resources available.

Mongolia's alternatives for solving the problems of modernization, democracy, and more international profile are also limited. Mongolia seems to be one of the few countries in the world where national sovereignty has always been dependent upon the nature of its social and political regime. The political and social choice of the Mongols determines their international posture and effects the guarantees of their independence. By consolidating the choice made in 1990 and working to implement a compatible development of the democratic institutions and the economy, Mongolia would achieve a breakthrough to join the wider world and come out of the shadow that its neighbors have been casting over Inner Asia for the past six centuries. It is a unique chance Mongols can not afford to miss. The nomadic individualism of the Mongols could become an important aspect of the country's democratic culture, and the geopolitical and geographic constraints could be reduced by turning the country into a meeting point of different civilizations and economies. In order to do that, Mongols need a coherent national strategy. 